\title{
DIFICULDADES E LIMITAÇÕES DE ENSINO NA EDUCAÇÃO DO CAMPO: REFLEXOS DA EDUCAÇÃO URBANA; ABAETETUBA-PA
}

\author{
DIFFICULTIES AND LIMITATIONS OF EDUCATION IN THE FIELD: \\ REFLECTIONS OF URBAN EDUCATION; ABAETETUBA-PA
}

\author{
Yvens Ely Martins Cordeiro ${ }^{1}$ \\ Rafael de Jesus Correa Quaresma ${ }^{2}$ \\ Gracilene Ferreira Pantoja ${ }^{3}$
}

\section{RESUMO}

Esse artigo é resultado de uma pesquisa realizada na Escola Prof. Basílio de Carvalho, localizada no centro comercial no município de Abaetetuba-PA. Tendo como objetivo identificar as principais dificuldades que interferem para a produção de um ensino que busque atender o aluno do campo. A Metodologia utilizada foi um Estudo de Caso, a partir de uma abordagem qualitativa, apoiando-se em pesquisa bibliográfica, questionários e roteiro semiestruturado. São usados vários elementos para justificar a ausência de didáticas voltadas a Educação do Campo. Contudo, o ensino na escola citada passa refletir justamente o currículo da educação urbana, colocando em plena marginalização educacional/social os alunos residentes do campo, os quais participam ativamente de aulas baseadas em concepções pautadas a realidade da cidade. Tornando-se uma prática de via dupla de conhecimentos e pressões ideológicas a todo momento.

Palavras-chave: Educação do Campo, Ausência de Didáticas, Educação Urbana, Abaetetuba-PA.

\section{ABSTRACT}

This article is the result of a research carried out at Escola Prof. Basilio de Carvalho, located in the commercial center in the municipality of Abaetetuba-PA. Aiming to identify the main difficulties that interfere with the production of a teaching that seeks to attend the student of the field. The Methodology used was a Case Study, based on a qualitative approach, based on bibliographical research, questionnaires and semi-structured script.

${ }^{1}$ Doutorado em Ciências Agrárias, Área de Concentração Agroecossistemas da Amazônia (2011), pelo Convênio UFRA / EMBRAPA. Mestrado em Ciências Agrárias, Área de Concentração em Biologia Vegetal Tropical, pela Universidade Federal Rural da Amazônia (2007). Graduação em Ciências Biológicas pela Universidade Federal do Pará (2003). Atua também como docente permanente do Programa de Pós Graduação em Cidades, Território e Identidades -PPGCITI/ UFPA. Tem experiência na área de Agricultura Familiar, Biodiversidade, Meio Ambiente e Educação no Campo.

${ }^{2}$ Graduação em licenciatura em Educação do Campo com ênfase em Ciências Naturais pela Universidade Federal do Pará - Campus Universitário de Abaetetuba. Bolsista do PIBID - DIVERSIDADE (2015 - 2018), Membro do Grupo de Estudo e Pesquisa Memória Formação Docente e Tecnologia (GEPEMe). Mestrando do Programa de Pós-graduação em Cidades, Territórios e Identidades pela UFPA.

${ }^{3}$ Graduação em Educação do Campo pela Universidade Federal do Pará (2018), Campus Universitário de Abaetetuba. Bolsista PIBID-Diversidade (2015-2016). Bolsista PIBIC (2017) Membro do Grupo de Estudos e Pesquisas Interdisciplinar em Ambiente, Território e Interculturalidade (GEPIATI). Atualmente integra ao Grupo de Estudos da Biodiversidade e Sustentabilidade na Amazônia Tocantina 
Several elements are used to justify the lack of didactics for Field Education. However, teaching at the school mentioned reflects the curriculum of urban education, placing in full educational / social marginalization the resident students of the field, who actively participate in classes based on conceptions based on the reality of the city. Becoming a dual track practice of knowledge and ideological pressures at all times.

Keywords: Field Education, Absence of Teaching, Urban Education, Abaetetuba-PA.

\section{INTRODUÇÃO}

O presente artigo é resultado de uma pesquisa desenvolvida no período de março de 2017 a fevereiro de 2018, e tem como objeto de estudo a Educação do Campo em uma escola em perímetro urbano no município de Abaetetuba-PA. O objetivo dessa pesquisa se faz mediante a necessidade de identificar as principais dificuldades que interferem para a produção de um ensino que busque atender os alunos do campo que acessam uma escola na cidade.

Para o desenvolvimento desse estudo a metodologia utilizada (descrita na sessão seguinte) foi um Estudo de Caso, por entender que a escola apresenta uma singularidade específica, uma escola em perímetro urbano, mas que atende um alunado entorno de $90 \%$ de estudantes residentes no campo, que fazem e refazem o trajeto campo-cidade-campo durante os dias letivos. A abordagem utilizada foi de cunho Qualitativa, e para o levantamento de dados foi utilizado Pesquisa Bibliográfica, além da utilização de questionários e roteiros semiestruturados, foram entrevistados três professores atuante no ensino fundamental.

A escola pesquisada estar localizada em perímetro urbano mais algumas características reforçam a legalidade de uma escola do campo, dentre estas, o alunado sendo quase que exclusivamente do campo (90\%), e de acordo com o decreto de $\mathrm{n}^{\mathrm{o}} 7.352$ de 04 novembro de 2010 que dispõem sobre a Política da Educação do Campo e o Programa Nacional de Educação na Reforma Agrária (PRONERA), determina que escola do campo é aquela situada em espaços rurais, de acordo com o Instituto Brasileiro de Geografia e Estatística (IBGE), ou aquela situada em perímetro urbano desde que atenda uma demanda predominante de populações do campo. 
Mas, a relação entre campo e cidade é marcada principalmente por aspectos de desigualdade, e nos âmbitos da educação é visível que a educação urbana sempre recebeu mais aplicação de investimento públicos por parte dos governos, que as escolas do campo. Saviani (1994), discutindo o trabalho como princípio educativo, nos demonstra que, "a cidade é tida como referência ao progresso e ao desenvolvimento, enquanto o campo como algo (...) atrasado, rústico, ou pouco desenvolvido" (SAVIANI; 1994, p. 05).

Nessa perspectiva as políticas públicas educacionais voltadas para o campo se estruturam a partir de duas determinações, uma que segue os moldes do sistema capitalista e outra que busca o seguimento da ótica urbana, porque é considerada mais desenvolvida. Do ponto de vista do capital, a educação no campo não oportuniza a estes sujeitos condições de mudança e sim de aceitação e submissão, na lógica urbana acontece a implantação da escola urbana no campo, onde se estrutura em consonância com o ensino empregado nas escolas da cidade, ocultando os próprios saberes das comunidades em que a escolas estão inseridas.

A Lei de Diretrizes de Bases da Educação Nacional - LDBEN 9394/96; prevê apenas uma adaptação dos conteúdos e da metodologia utilizada pelos professores em relação aos saberes dos alunos do campo. Contudo não há valorização do trabalho, dos modos de vida e da cultura rural nas escolas no/do campo. É evidente que o ensino urbano segue uma lógica que não é a mesma do campo, muito em função da padronização do currículo urbano, e na perspectiva da educação do campo, ao contrário disso, se visa um modelo de ensino que dialogue com a realidade dos educandos.

\section{METODOLOGIA}

O caráter metodológico deste estudo cumpre-se em duas etapas, a primeira cometida por Pesquisa Bibliográfica na plataforma Google Acadêmico, partindo de palavras-chave como: Educação do campo, Educação Curricular e Currículo da Escola do Campo, estas que delimitaram o material para a seleção da bibliografia utilizada. Segundo Gil (2008), “a pesquisa bibliográfica é desenvolvida a partir de material já elaborado, constituído principalmente de livros e artigos científicos" (GIL; 2008, p. 50). Esse tipo de pesquisa repara 


\section{Revista \\ Debates Insubmissos}

a essência do texto produzido, pois possibilita ao investigador o contado com diferentes estudos e interpretações referentes ao tema estudado.

A segunda e mais importante etapa metodológica deste estudo se caracteriza como um estudo de caso, que para Yin (2001), "é uma investigação empírica que investiga um fenômeno contemporâneo dentro de seu contexto da vida real, especialmente quando os limites entre o fenômeno e contexto não estão claramente definidos" (YIN; 2001, p. 32). Segundo Fonseca (2002), o estudo de caso se caracteriza pela análise de um determinado grupo social, em busca pela compreensão do ponto de vista do entrevistado, para a proposição da realidade vivida. Como propõem.

O estudo de caso pode decorrer de acordo com uma perspectiva interpretativa, que procura compreender como é o mundo do ponto de vista dos participantes, ou uma perspectiva pragmática, que visa simplesmente apresentar uma perspectiva global, tanto quanto possível completa e coerente, do objeto de estudo do ponto de vista do investigador. (FONSECA; 2002, p. 33)

A abordagem utilizada neste estudo foi de caráter qualitativa, aliando-se a necessidade de compreender os sujeitos investigados, no que se estabelece como uma conexão com a realidade de investigação. Para Minayo (2002), a abordagem qualitativa abrange muito mais que dados quantificados em tabelas ou gráficos, por se expressar através das relações que o pesquisador desenvolve com o grupo objeto de investigação, pois, é através dos dados de pesquisa que se pode entender o outro.

Como instrumentos para coleta de dados, esta pesquisa contou com a utilização de questionários e roteiros semiestruturado. Triviños (1987), defende a importância da entrevista semiestruturada, pois possibilita ao pesquisador um contato amplo com as respostas dos informantes, o que determinará para uma melhor análise dos dados coletados. Participaram deste estudo três professores atuantes no ensino fundamental da escola Professor Basílio de Carvalho, identificados como PROFESSOR-1, PROFESSOR-2, PROFESSOR-3 para análises dos dados. 


\section{1. Espaço da Pesquisa}

A pesquisa foi realizada com professores da Escola estadual de Ensino Fundamental e Médio Professor Basílio de Carvalho, localizada no centro comercial do município de Abaetetuba-PA, local estratégico para acolher inúmeros alunos do campo, alunos estes que se deslocam todos os dias de suas residências situadas nas ilhas e estradas do município. Esta escola é escolhida pelo pais pelo fato de viabilizar a vida dos seus filhos, devido ser a escola mais próxima da feira do município, sendo o porto para os alunos ribeirinhos que fazem o trajeto ilha-cidade, e também por ser em frente à praça Francisco Azevedo Monteiro ou Praça da Bandeira, que é o ponto de ônibus para quem vem das estradas.

Figura 1. A. Escola de Ensino Fundamental e Médio Professor Basílio de Carvalho.

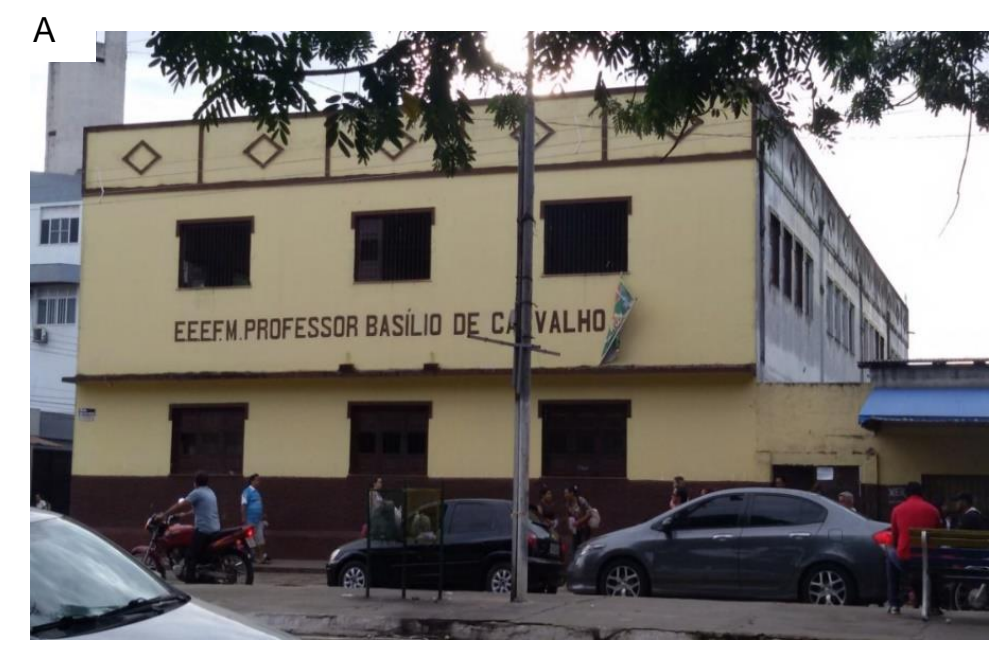

Fonte: Acervo da pesquisa (2017)

A escola atende uma diversidade de alunos, entre urbanos e rurais, assim possui um alunado específico e diferenciado de outras escolas do mesmo município, este último grupo em sua maioria, um percentual entorno de $90 \%$, a escola no turno da manhã possui um total de 16 (dezesseis) turmas, sendo 6 (seis) do ensino médio e 10 (dez) do ensino fundamental. A escola em sua estrutura predial conta com: laboratório de informática, uma biblioteca, 


\section{Debates Insubmissos}

laboratório multidisciplinar, quadra poliesportiva, sala dos professores, sala da coordenação pedagógica, sala da direção, lanchonete, salão de recreação, copa, além dos banheiros.

Uma característica da escola que não passa despercebida é o fato de todas as pinturas nas paredes da escola remeterem ao meio rural, são inúmeras as figuras que retrata o dia-a-dia dos moradores do campo, imagens de personagens e trabalhadores do cenário rural, assim considera-se que a escola se reconhece dentro das particularidades do campo, porém as práticas desenvolvidas nessa perspectiva do campo são quase que inexistentes. Por isso a funcionalidade deste estudo, entender o posicionamento dos principais agentes da escola, que são os professores, conhecer o seu ponto de vista em relação a didática do campo.

Figura 2. Pinturas nas Paredes da Escola remetendo a vida no Campo. A. Representação do trabalho oleiro. B. Representação do trabalho com a pesca e captura de camarões. C. Representação da Prática das benzedeiras.
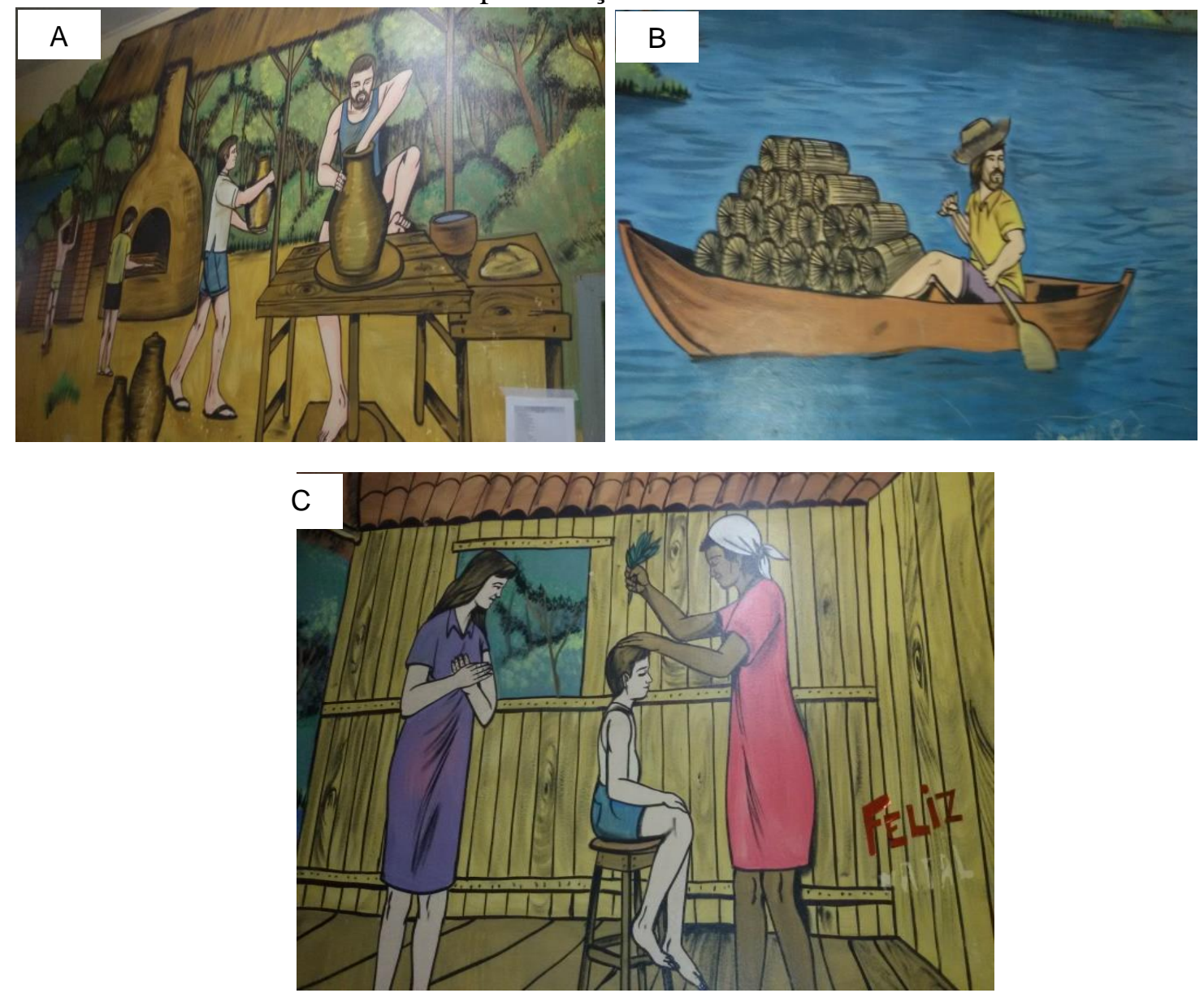

Fonte: Acervo da pesquisa (2017). 


\section{CONCEPÇÕES SOBRE O CURRÍCULO E EDUCAÇÃO DO CAMPO}

O currículo escolar nos remete há um plano organizativo, onde os conteúdos se alinham, conteúdos que fomentam a obrigatoriedade do trabalho docente e de certa forma a aprendizagem dos educandos, o currículo é o fio condutor que permeia a verdadeira essência da escola. E como um fio, que pode transferir cargas positivas e negativas, este também conduz conceitos de vidas, valores e pressões ideológicas.

Conforme Santos (2015);

[...], o currículo é resultado de uma seleção que envolve um conjunto de práticas relacionadas à transmissão dos saberes e conhecimentos pretendidos. Nesse sentido, a questão central da teoria do currículo é compreender por que determinados conhecimentos são excluídos do currículo, enquanto outros são aceitos e validados na constituição das identidades e diferenças. (SANTOS; 2015, p. 50)

Para o autor, o currículo é resultado de uma seleção de conhecimentos associando-se a um sistema mascarado de transmissão de interesses ideológicos, quando considera a validade de um único modelo de ensino, configurando a uma padronização social interessada, e reproduzindo identidades igualitárias e que se deseja pelo modelo hegemônico social. Por isso nossas escolas no e do campo reproduzem a concepção urbana de educação.

Contudo, Silva (2010), afirma que:

Nas discussões cotidianas, quando pensamos em um currículo pensamos apenas em conhecimento, esquecendo-nos de que o conhecimento que constitui o currículo está inextricavelmente, centralmente, vitalmente, envolvido naquilo que somos, naquilo que nos tornamos: nossa identidade, na nossa subjetividade (SILVA; 2010, p. 15).

Silva (2010), considera o currículo como sinônimo da objetividade, e que os conhecimentos transpassados pelo currículo induz a nossa formação educacional e social, para o mesmo, o currículo está intrinsicamente relacionado aos conhecimentos que norteiam a vida do estudante, muito conveniente com o sistema capitalista na busca e na formação da mão de obra para o mercado, dessa forma expelindo conhecimentos e saberes dos educandos do campo que chegam a escola, porque não são considerado válidos, como bem propõem Santos (2015), quando refere-se a aceitação de tais conhecimentos (urbanos) e a exclusão de outros (campo) na estruturação dos currículos atuais. 


\section{Revista \\ Debates Insubmissos}

Segundo, Moreira \& Silva (1994), “o currículo não é um elemento inocento e neutro de transmissão desinteressada do conhecimento social. O currículo está implicado em relações de poder, o currículo transmite visões sociais particulares e interessadas, o currículo produz identidades individuais e sociais particulares" (MOREIRA \& SILVA; 1994, p. 08).

Arroyo; Caldart \& Molina (2008), acrescentam que;

A cultura hegemônica trata os valores, as crenças, os saberes do campo de maneira romântica ou de maneira depreciativa, como valores ultrapassados, como saberes tradicionais, pré-científicos, pré-modernos. Daí que o modelo de educação básica queira impor para o campo currículos da escola urbana, saberes e valores urbanos, como se o campo e sua cultura pertencessem a um passado a ser esquecido e superado. (ARROYO; CALDART; MOLINA; 2008, p. 78-79)

Para estes autores, a cultura urbana implantada nas escolas do campo, responde a uma necessidade mascarada da sociedade hegemônica de estabelecer uma padronização da modernidade advinda dos centros urbanos, que mistifica um modelo único de ensino a ser seguido, nesse caso, ignorando todo um contexto que se inseri não só a escola como também os alunos do campo e suas vidas.

Para Pimentel (2007);

[...] o currículo é, antes de tudo, uma configuração dos modos de vida de habitar o mundo, por isso mesmo não pode ser pensado fora dos limites e possibilidades de sentir, agir e pensar a humana-idade que faz as histórias do presente no solo sempre fértil e fecundo da escola e de todos os espaços em que o viver comum inspira e pratica a educação. (PIMENTEL; 2007, p. 20).

Como defende Veiga (1995);

[...] o currículo é um instrumento de confronto de saberes: o saber sistematizado, indispensável à compreensão crítica da realidade, e o saber de classe, que o aluno representa e que é resultado das formas de sobrevivência que as camadas populares criam. Valoriza o saber de classe e coloca como ponto de partida para o trabalho educativo. (VEIGA; 1995, p. 82)

O currículo que se pensa para as escolas no/do campo é aquele que compartilham dos mesmos significados, intrínsecos a realidade de todos, levando em conta os saberes, as vivências e os conhecimentos dos alunos, um currículo desenvolvido para autenticar uma identidade ora marginalizada pelo sistema padronizado e hegemônico de sociedade. 


\section{norstat 0 \\ Debates Insubmissos}

Santos (2009), considera que;

[...] os conteúdos curriculares devem permitir que os alunos desenvolvam sua capacidade de argumentação, de questionamento, de crítica e sua capacidade de formular propostas de solução para problemas detectados. [...] é fundamental que o currículo trabalhe com habilidades que vão além do desenvolvimento cognitivo e envolvam diferentes campos da cultura, garantindo a presença de produções culturais dos mais diferentes grupos sociais e culturais, de tal modo que os estudantes sejam capazes de lidar com a diferença, valorizando e respeitando a cultura do outro, condição necessária para a vida em uma sociedade realmente democrática. (SANTOS; 2009, p. 13-14)

Santos (2009), sugere um currículo que “[...] busque a integração de conteúdos de diferentes campos, rompendo com a organização disciplinar, que se articule com os problemas da vida cotidiana, buscando formas de trabalho que permitam ao aluno construir conhecimento, bem como diferentes habilidades intelectuais, formas de conduta e valores" (SANTOS; 2009, p. 13).

O currículo das escolas no/do campo deve "se alicerçar no reconhecimento e na afirmação da diversidade sociocultural, contribuindo com uma formação pautada na convivência das diferenças e na participação do conjunto de seus sujeitos, grupos e populações nos rumos de um projeto [...] de desenvolvimento territorial inclusivo, sustentável e solidário" (CORDEIRO; 2010, p. 60).

Para Lima (2013), o currículo da educação do campo "se constitui a partir das experiências e das vivências dos alunos no contexto do campo, dos diálogos estabelecidos com as ações e mobilizações desenvolvidas pelos movimentos sociais, bem como, com os saberes culturais e as tecnologias sociais produzidas entre gerações, tendo em vista que esses saberes e práticas são fundamentais para a formação dos jovens enquanto cidadãos" (LIMA; 2013, p. 615).

Saviani (2003), nos coloca que;

O processo de construção do currículo deve estar para além da dinâmica de seleção e organização dos conteúdos, voltando-se principalmente para redefinição do papel da escola. Nesse processo, os conteúdos precisam ser pensados, não como verdades absolutas e neutras, mas como saberes históricos e culturais construídos socialmente a serem questionados e confrontados com as experiências dos alunos, possibilitando a produção de novos conhecimentos produzidos "a partir do velho, negando-o e 


\section{sorstat \\ Debates Insubmissos}

transformando-o num processo dialético de continuidade/ruptura" (SAVIANI, 2003, p. 73).

Sobre a valorização do currículo vivenciado pelos alunos do campo nos diferentes espaços sociais de educação, Santos (2015), considera que;

[...], na crença de podermos denotar um currículo "latente" da socialização escolar, que no sentido abstrato da palavra encontra-se oculto, mas que pode permear toda dimensão sócia cognitiva e cultural da educação. [...], a escola é por natureza um espaço privilegiado de saberes e culturas que circulam livremente, porém que precisam ser naturalizadas (familiarizadas) no currículo. Entretanto, esse processo de naturalização que deveria ser fruto de todos os grupos acaba por se tornar uma tradição seletiva da cultura hegemônica, que define o que é valido e obsoleto no currículo. Nesse sentido, a escola e o currículo se tornam espaços de legitimação da cultura hegemônica, à medida que o conhecimento é uma seleção feita pelos grupos que detêm o poder. (SANTOS; 2015, p. 61)

Para o autor, a escola é um espaço indissociável a construção de identidades, considera o currículo integrado aos conhecimentos dos educandos como uma referência para uma efetiva aprendizagem dentro do contexto dos quais os alunos estão integrados, mas que precisam ser aceitos pela escola como parte do processo educacional desses sujeitos, compreendendo toda a dimensão da realidade campesina e sua participação na sociedade, mas que infelizmente encontram-se ocultos pelo sistema gerador hegemônico social, que não leva em consideração o contexto e a realidade dos estudantes do campo, fazendo jus a uma seleção do currículo urbano totalmente excludente de conceitos e conhecimentos do campo na escola.

Ainda nesse mesmo sentido Moreira \& Silva (1994), explicam que;

O currículo nunca é apenas um conjunto neutro de conhecimentos, que de algum modo aparecem nos textos e nas salas de aula de uma nação. Ele é sempre parte de uma tradição seletiva, resultado da seleção de alguém, da visão de algum grupo acerca do que seja conhecimento legítimo. É produto de tensões, conflitos, concessões culturais, políticas e econômicas que organizam e desorganizam um povo. O que conta como conhecimento, as formas como ele está organizado, que tem autoridade para transmiti-lo, o que é considerado como evidencia apropriada de aprendizagem [...]. (MOREIRA; SILVA, 1994, p. 59)

Arroyo (2013), completa que;

As ausências dos sujeitos populares não se dão por ingênuo esquecimento, mas têm uma intencionalidade política, fazem parte dos processos políticos de segregação 


\section{novist \\ Debates Insubmissos}

desses coletivos nos diversos territórios sociais, econômicos, políticos e culturais. Suas ausências nos centros tidos como produtores e transmissores únicos do conhecimento legítimo, do saber sério, válido, objetivo, científico que são as disciplinas e os ordenamentos curriculares é mais um dos mecanismos históricos de mantê-los ausentes, inexistentes como sujeitos sociais, políticos, culturais e intelectuais. (ARROYO; 2013, p. 143)

Segundo Forquin (1992), o currículo escolar não dispensa o contexto social do educando, para o autor é uma relação que se completa, como segue;

[...] aquilo que é realmente aprendido, retido e compreendido pelos alunos não corresponde tampouco aquilo que os docentes ensinam (currículo ensinado) ou creem ensinar, e que esta inadequação pode se tornar por sua vez, objeto de uma investigação sociológica, pois recepção da mensagem (currículo aprendido) depende do contexto social e cultural. (FORQUIN; 1992, p. 32)

\section{DIFICULDADES E LIMITAÇÕES DE ENSINO NA EDUCAÇÃO DO CAMPO}

As concepções sobre o currículo escolar segundos os professores entrevistados:

Eu entendo que o currículo é o que rege a vida da escola e também de certa forma a vida dos alunos. Porque é o que será trabalhado e o que os alunos irão aprender. Não existe qualquer envolvimento dos pais e alunos nessa seleção de conteúdos a serem repassados, é uma utopia. (PROFESSOR-1)

A proposta curricular aqui é puramente urbana, pelo menos na minha disciplina é assim, não existe uma, uma proposta que inclua conceitos e valores da educação do campo, eu não sei deve partir da escola como um todo ou por iniciativa de cada professor, o currículo em si é o que dá vida a qualquer escola, é o que será trabalhado durante o ano todo com os alunos. (PROFESSOR-2)

É o que dá sentido à nossa função da escola é o que nos prepara, é como se fosse esse roteiro que você está utilizando, que você segue uma ordem das perguntas, você não pula para o final e depois volta para o início você segue uma sequência assim o currículo. (PROFESSOR-3)

Para ambos entrevistados o currículo é o que dá sentido as atividades da escola, é o que conduz o trabalho docente, um caminho a ser percorrido e, o que os alunos irão aprender, não há influências externas para a seleção dos conteúdos disciplinares a serem ministrados pelos professores, é um trabalho apenas de uma esfera educacional majoritária, nesse caso a secretaria de educação do estado, um estágio educacional que trata todas as escolas como iguais, seja aluno do campo ou da cidade, o que acarreta para uma negligência contra os alunos do campo na escola urbana. 


\section{Revista \\ Debates Insubmissos}

O PROFESSOR-2, destaca que o currículo da escola segue uma proposta estritamente urbana, por isso não se evidencia aspectos ligados a educação do campo, e revela-se um questionamento em sua narrativa, em relação a introdução de conceitos ligado as vivencias dos educandos do campo e as relações com os conteúdos curriculares disciplinar.

Já o PROFESSOR-3, coloca que o currículo escolar além de estabelecer significado ao trabalho do professor na escola se instrumentaliza como um roteiro que induz a uma sequência, uma ordem, alicerçada há uma concepção de objetividade da transposição dos conteúdos definido no documento aos alunos.

Como evidencia Giroux (1997);

Na concepção tradicional do currículo, o conhecimento é imposto aos sujeitos, sem possibilidade de questionamentos, "divorciado do significado humano e da troca intersubjetiva [...], separado do processo de geração de nosso próprio conjunto de significados, um processo que envolve uma relação interpretativa entre conhecer e conhecido" (GIROUX; 1997, p. 45).

Sobre a proposta curricular da escola ambos professores entrevistados respondem:

O currículo que chega até nós, é um currículo idealizado pela SEDUC. É com base nesse currículo que trabalhamos, eu as vezes faço modificações, altero a ordem dos conteúdos e as vezes consigo trabalhar todo, as vezes não, agora com toda essa situação de greve e paralização fica mais difícil ainda. [...], não existe uma preocupação com a realidade de cada escola. (PROFESSOR-1)

O PROFESSOR-1, comenta que o currículo que chega a escola é um documento padronizado pela Secretaria de Educação do Estado do Pará (SEDUC-PA), para todas as escolas no município de Abaetetuba, entre escolas urbanas ou rurais, é um conceito idealizado que não compreende as especificidades da região amazônica, que não considera a geografia espacial em que as escolas se inserem, contextos de escolas que se diferenciam de acordo com a paisagem e seu alunado.

Para o PROFESSOR-2, o currículo da escola;

[...], são conteúdos prontos formalizados, e eu não vejo preocupação de reformulação ou de inclusão, por exemplo da educação do campo, é tipo assim a educação infelizmente sempre valorizou a cidade então o conteúdo em si irão priorizar estes sujeitos que moram na cidade. (PROFESSOR-2)

Para o mesmo, a padronização do currículo escolar e a maneira como a escola o trata, estreitamente fechado, pronto ou acabado exclui quaisquer possibilidades de inclusão da 
educação do campo como uma vertente também a ser trabalho na escola, comenta que a e escola se mostra em uma constante inércia sobre a educação do campo, sobre a valorização do contexto rural na escola, sem qualquer envolvimento com a realidade concreta dos educandos do campo. Por isso frisa que a educação e principalmente o currículo tende a visar a educação urbana e estes alunos.

O PROFESSOR-3, comenta sobre o currículo da escola;

É um currículo urbano sem nenhuma aproximação com o campo, eu falo assim pela minha disciplina, eu mesmo faço relação dos conteúdos com os conhecimentos do campo, devido eu ter um conhecimento prévio com a realidade do campo, a nossa vida inteira a gente absorve né, informações e no momento da aula a gente faz o que pode. (PROFESSOR-3)

Para o professor entrevistado o que se reproduz na escola é um currículo urbano, em que, não há relação com as vivencias dos alunos do campo, pelo que se interpreta segundo a narrativa, segue de cada professor fazer essa relação, mas como bem argumenta, é necessário ter um conhecimento de tais realidades para poder fazer essa contextualização recorrente aos alunos do campo, o que se compreende que esse processo que envolve a educação e os alunos do campo restringem-se a um devida sensibilidade de cada professor em conhecer ou buscar conhecer outras perspectivas além da urbana, nesse caso a realidade campesina, que é subtraída pelo contexto urbano de educação na referida instituição.

Sobre a relação do currículo com a realidade dos alunos do campo os entrevistados respondem;

Olha se pararmos para pensar sobre os conteúdos que se relacionam com essa realidade do campo, a gente acaba encontrando uma variedade rica de assuntos, em algumas disciplinas mais em outras menos, acredito eu [...]. É assim, na convivência com os alunos a gente acaba apreendendo, na verdade com eles. (PROFESSOR-1)

Freire (1996), explica a importância do contato pessoal entre os indivíduos no seio da comunidade escolar, considera o diálogo e as trocas de experiências entre professor-aluno como espaço fundamental para o desenvolvimento de ambos sujeitos na prática docente e na formação social/pessoal, para o autor "o educador que escuta aprende a difícil lição de transformar o seu discurso, às vezes necessário, ao aluno, em uma fala com ele" (FREIRE; 1996, p. 71).

Ainda nesse mesmo sentido Freire (1996), acrescenta que; 


\section{sorstat 6 \\ Debates Insubmissos}

Uma das tarefas mais importantes da prática educativo-crítica é propiciar as condições em que os educandos em relação uns com os outros e todos com o professor ou a professora ensaiam a experiência profunda de assumir-se. Assumir-se como ser social e histórico, como ser pensante, comunicante, transformador, criador, realizador de sonhos, capaz de ter raiva porque capaz de amar. Assumir-se como sujeito porque capaz de reconhecer-se como objeto (FREIRE; 1996, p. 23)

Para os professores 2 e 3 ;

Se pensar estes até se relacionam, por exemplo na minha disciplinada pode se relacionar muita coisa, porque trata de questões do campo, mas dificilmente eu faço (eu não vou mentir), porque eu não tinha essa visão, eu até agradeço por ter me escolhido para o teu trabalho, porque eu não sei o resultado da tua pesquisa, mas eu já sei o que ela instigou em mim, [...], me instigou a querer fazer a educação do campo. (PROFESSOR-2)

[...], eu entendo que é importante trabalha na perspectiva do campo também e não só da cidade, porque aqui são indivíduos do campo e da cidade. (PROFESSOR-3)

Nas narrativas nota-se que ambos entrevistados expressam a importância da relação do currículo escolar com a realidade dos alunos do campo, porém em suas falas também expressam que estas relações de conhecimentos ficam somente nos pensamentos destes, devido na prática, no dia a dia da sala de aula não fazerem acontecer. Além do reconhecimento da importância da educação do campo na escola pelos professores, é necessário que as ações deixem o plano de pensamentos e sejam colocados em prática no cotidiano escolar.

Para os professores muito dos conteúdos trabalhados na escola induz a essa possível relação de conhecimento, entre os conteúdos que são necessários a aprendizagem dos educandos com a veracidade da realidade que os representam, mas devido o contexto que a escola se insere e se reconhece, nesse caso como uma escola urbana, impossibilita que tais pensamentos se corporifiquem, ganhem forma sejam executados, muito em função do sistema ao qual tanto a escola como os professores estão submetidos, que visa somente conceitos urbanos, em uma escola onde a diversidade faz-se presente, contendo alunos urbanos, ribeirinhos, de comunidades de terra firma, e quilombolas, alunos de diferentes localidades no município de Abaetetuba.

Os saberes do currículo oculto segundo os entrevistados: 


\section{novist \\ Debates Insubmissos}

[...], eu te confesso que é a primeira vez que eu escuto essa expressão "currículo oculto", eu não fazia a menor ideia que este termo era usado para representar o conhecimento dos alunos do campo. (PROFESSOR-1)

Desse modo, percebe-se que os conhecimentos dos alunos tornam se invisíveis perante as ações docente, não há uma preocupação com os saberes empíricos destes que chegam as escolas de diferentes comunidades, a expressão currículo oculto que em seu significado passaria a acrescentar as experiências e vivências do cotidiano do aluno na escola como requisito também de formação, torna-se uma expressão que realça puramente sua denotação de ocultação destes saberes, já que pouco se discuti esta relação na escola.

O PROFESSOR-2 também não sabe expressar o significado de tal expressão, seu entendimento por currículo reduz-se ao currículo urbano, ao planejamento anual, a uma estruturação dos conteúdos, mas após ter noção do que se trata, revela que o currículo também deve abranger dos diferentes sujeitos que a escola possui, numa perspectiva de inclusiva e dialógica entre as realidades da escola.

Sobre o currículo oculto eu não sei nem te responder, o currículo eu sei, que é esse planejamento e estruturação dos conteúdos a serem trabalhados durante o ano, mas essa questão do oculto eu não faço ideia do que seria [...], assim eu entendo que é importante trabalhar também na perspectiva do campo e não só da cidade, porque aqui são indivíduos do campo e da cidade. (PROFESSOR-2)

O PROFESSOR-3, demostra também não conhecer do que se trata a expressão “currículo oculto", mas em síntese pondera que o currículo é o que orienta a didática docente, lembra que o currículo em si dificilmente se contextualiza com os aspectos do campo, por evidenciar o ensino na cidade, e após o conhecimento do sentido da expressão por meio de minha intervenção, considera como uma experiência fundamental para envolver os alunos do campo nas aulas, e nas atividades por se tratar de questões de seus cotidianos.

Bom, eu não sei o que significa essa expressão, mas o currículo é o que nos orienta, dificilmente vem no currículo um conteúdo que faça essa conexão como o campo, porque é um currículo pensado para a cidade. [...], no que você explicou agora o currículo oculto é fundamental para esses alunos, porque irá trata de uma realidade deles enquanto alunos do campo. (PROFESSOR-3)

No entanto, após análise das narrativas percebe-se que ambos entrevistados desconhecem o significado da expressão saberes do currículo oculto, devido não terem um 


\section{Revista \\ Debates Insubmissos}

maior envolvimento com ações voltadas para o contexto do aluno do campo, que em suma respondem no significado abrangente do currículo urbano, padrão e uniforme. Em contrapartida o currículo oculto deve estar em sintonia com os conteúdos escolares, uma relação que permita aos professores e alunos uma intensa troca de experiências, dando visibilidade aos sujeitos campesinos no contexto escolar que estão todos submetidos.

Os professores entrevistados expressam as principais dificuldades para a efetivação de um currículo em conformidade a realidade dos alunos do campo;

[...], acho que a principal dificuldade é o nosso tempo que se tornou curto demais, e impede o tempo para a pesquisa, planejamento e a criatividade para inovar e trazer didáticas de acordo com essas realidades e os conhecimentos dos alunos, até porque são vários níveis de escolaridade e cada um desse necessita de uma atenção especial. (PROFESSOR-1)

O PROFESSOR-1, coloca que a principal dificuldade que impede a culminação do ensino e dos conteúdos escolares conectados a realidade dos alunos do campo se dá muito em função do tempo disponível do professor hoje em dia, que para este se tornou reduzido perante as atividades que desenvolvem, comparando-os como máquinas de transmissão de conhecimentos, o qual justifica que o tempo do professor no cotidiano da sala de aula, limita as atividades de pesquisa, de planejamentos de aulas e principalmente o envolvimento com didáticas voltadas para a relação dos saberes dos alunos do campo, devido a acessibilidade que o currículo urbano e os livros didáticos nos oferecem, no entanto precisa-se de tempo como pondera o professor entrevistado para o planejamento das aulas aos diferentes níveis escolares.

Ainda se falando das dificuldades impostas pelos professores que impedem a contemplação do ensino disciplinar da escola Professor Basílio de Carvalho a realidade vivida pelos alunos do campo, o PROFESSOR-2, considera que;

A principal dificuldade são as dificuldades que colocamos, o fácil acesso também as aulas, por exemplo, para ocorrer essa adaptação, é..., necessita de reflexão, para se trabalha o que é importante para o aluno, e também conhecer essa realidade mais de perto, com pesquisas e até mesmo vivências se possível, tudo isso levaria tempo e disposição de cada professor, e as aulas ditas urbanas já estão prontas, basta 10 minutos na frente de um computador e já se tem a aula do dia. (PROFESSOR-2) 
Araújo \& Silva (2011), consideram que "a reflexão sobre o trabalho possibilita ao ser humano identificar de que maneira está inserido na sociedade e se as práticas sociais constituintes destas formas de inserção satisfazem as suas necessidades [...], a análise do próprio modo de vida e trabalho e as práticas sociais transformadoras aí engendradas são elementos indispensáveis no contexto de formação de professores" (ARAÚJO; SILVA; 2011, p. 43).

Os autores destacam que é na reflexão da prática exercida que o docente, se contextualiza em busca da sua constante ressignificação de seu ato, e o modo como se inserem no contexto que tanto o professor quanto os alunos estão submetidos, bem como questiona Freire (1996), “como ensinar, como formar sem estar aberto ao contorno geográfico, social, dos educandos?"(FREIRE; 1996, p. 87).

O PROFESSOR-2, acrescenta em sua narrativa um elemento muito importante para esse estudo, quando refere-se ao fácil acesso que os professores possuem aos conteúdos disciplinares, tanto nos livros didáticos, estes de caráter monocrático e arbitrário que compreendem apenas uma realidade a ser estudada, nesse caso explicitamente a realidade da escola urbana, como se todos os sujeitos compartilhassem de uma só realidade, quanto à disponibilidade dos conteúdos em sites da internet, que teoricamente reduz a sensibilidade do trabalho do professor conectado a realidade dos alunos.

Destacando em sua fala a necessidade da reflexão docente que induz a compreender a necessidade do trabalho dentro da perspectiva do aluno do campo, e também a integração do professor as realidades dos alunos por meio de pesquisas ou até mesmo por vivências comunitárias, concordando com o PROFESSOR-1, quando refere ao tempo disponível de cada professor. Ambos entrevistados colocam o tempo como elemento principal que impede essa aproximação da realidade campesina na escola.

Nessa mesma concepção apresentada pelo PROFESSOR-2, Melo (2011), faz uma crítica regente a formação dos professores e a iniquidade com quem tratam os valores e conceitos dos alunos do campo na escola urbana, quando afirma que;

A educação rural, na maioria das vezes, contempla currículos urbanos, ficando aquém da realidade dos alunos rurais. Assim, as pessoas desse meio acabam carentes de conhecimentos e habilidades que lhes proporcionam maior eficiência no trabalho, 


\section{novitt

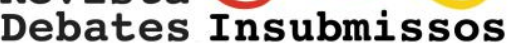

agilidade na resolução de problemas cotidianos. Isso acontece pela falta de preparo e formação dos professores que trabalham nas escolas do meio rural. Eles têm conhecimentos voltados aos conteúdos que são contemplados no currículo urbano, ou no livro didático, no entanto da vida prática, do cotidiano dos alunos, pouco sabem. (MELO; 2011, p. 35)

Ainda nesse mesmo contexto que nos coloca Melo (2011), Arroyo (2013), considera que;

[...] os currículos e os livros didáticos são pensados como espaços de saberes, de conhecimentos e de concepções, deslocados de vivências da concretude social e política. Sobretudo, deslocados dos sujeitos humanos produtores dessas vivências sociais e dos conhecimentos. Estes aparecem em um vazio social, produzidos e reproduzidos, ensinados e aprendidos sem referência a sujeitos, contextos e experiências concretas. Consequentemente as didáticas de seu ensino aprendizagem são abstratas, válidas para todo conhecimento e para todo aluno ou coletivo. Válidas para toda vivência, todo contexto social e cultural. (ARROYO; 2013, p. 76-77)

Já a narrativa do PROFESSOR-3 se diverge das justificativas colocadas anteriormente pelos 02 (dois) primeiros professores entrevistados;

Seria a formação de professores, por exemplo, eu não tive essa formação voltada para o campo, mas devido esse meu envolvimento com os alunos eu já conheço parte da vida deles, o que fazem, de onde vem, o que produzem essas coisas. Acho que devemos primeiro conhecer os alunos a realidade deles. [...], e que poderiam ser fomentada pela a escola durante a semana pedagógica que acontece no início do ano letivo com nós professores. (PROFESSOR-3)

Para o mesmo, a principal dificuldade perpassa pela formação dos professores, quando ambos não conhecem a realidade plural que cerca o município de Abaetetuba, pondera, que não teve uma formação inicial, propicia e adequada ao exercício do ensino para a dimensão do campo e as formações que acontecem na escola durante a semana pedagógica não enaltece discussões e reflexões voltadas para didáticas com os alunos do campo, mas segundo, seu envolvimento com os alunos passa a compreender a realidades destes, colocando como ponto inicial para o trabalho na perspectiva do aluno do campo o conhecimento da realidade.

Sobre a formação de professores para a educação do campo, o Decreto ${ }^{\circ}$ 7.352/2010 que dispõe sobre as políticas da educação do campo, no quarto parágrafo do artigo $1^{\circ}$ evidencia que;

A educação do campo concretizar-se-á mediante a oferta de formação inicial e continuada de profissionais da educação, a garantia de condições de infraestrutura e transporte escolar, bem como de materiais e livros didáticos, equipamentos, laboratórios, biblioteca e áreas de lazer e desporto adequados ao projeto político 


\section{Revista (1) \\ Debates Insubmissos}

pedagógico e em conformidade com a realidade local e a diversidade das populações do campo. (DECRETO No 7.352/2010)

Para Araújo \& Silva (2011), a formação dos profissionais da educação do campo deve;

[...] levar em consideração liberdade de consciência para o diálogo e para as decisões em conjunto, o que implica em desvendar a realidade e se organizar para transformá-la, sintetizando os interesses dos grupos sociais, o que compreende a lógica freireana do ser para ser mais, onde o democrático, o participativo, se aprende na prática. (ARAÚJO; SILVA; 2011, p. 36)

Nas narrativas presentes aparecem vários elementos que são usados pelos entrevistados para justificar a ausência de didáticas correlacionadas ao ensino para os estudantes que se deslocam diariamente da comunidades rurais, dentre estes: a falta de tempo do professor convencionados a várias atividades no dia a dia na escola, o acesso fácil ao currículo urbanos e os conteúdos disciplinares nos livros didáticos e em pesquisas na internet, o monocratismo das realidades como única e igualável, a resistência em reconhecer a realidade dos educandos como um potente elemento de formação, restrição a reflexão docente amparada pela particularidade urbana de educação e a falta de formação dos profissionais docente da instituição no que envolve a educação do campo.

\section{CONSIDERAÇÕES FINAIS}

A reprodução conceitual do campo como lugar de atraso, influencia para uma constante negação da identidade do aluno enquanto sujeito do campo, passando a enaltecer e conviver arbitrariamente com uma cultura que não é sua, tais aspectos contribuem para o desencadeamento sinonímico do campo como lugar de sofrimento, da vida difícil, passando a ser reproduzido pela própria juventude do campo com influencias significativas de um currículo homogêneo, condensado exclusivamente a educação urbana.

O currículo escolar passa a refletir sobre a construções de identidades, muito alicerçado à uma gama de interesses do padrão citadino, considerando que o currículo preza uma constante universalização de cultura urbana, que mitifica a trata a cultura rural com verdadeira impotência dentro das escolas no/do campo.

Nesse sentido, a escola e a educação do campo devem romper a dicotomia da reprodução, e assumir caráter autônomo de ensino, visando uma adaptação ou adequação da 
proposta curricular integrado as especificidades dos alunos, uma proposta que valorize o conhecimento dos alunos do campo ocultos pelo modelo urbano de ensino. A escola deve seguir na perspectiva dos sujeitos que fazem a escola do campo, explorando as condições de quem vive no e do campo, assumir um verdadeiro caráter de produção, de um ensino que para além dos conteúdos disciplinares contribua para a vida social de cada aluno.

Desse modo, a educação do campo na escola investigada passa refletir justamente o currículo da educação urbana, colocando em plena marginalização educacional e até mesmo social os alunos residentes do campo, os quais participam ativamente de aulas baseadas em concepções pautadas a realidade da cidade, introduzindo por sua vez ideologias da cultura hegemônica nos sujeitos e também no campo já que ambos estudantes realizam esses trajeto campo-cidade e vice-versa. Tornando-se uma prática de via dupla de conhecimentos e pressões ideológicas a todo momento.

No que se insere as dificuldades para tamanha efetividade do ensino que contemple os alunos do campo, ressalta-se a limitação do currículo padronizado, resultante de uma seleção de conhecimentos que notavelmente não congregam com as especificidades que se busca através da educação do campo, ao contrário preza-se muito mais formar um modelo de sujeito baseados por uma média do que educar para a realidade, para a vivência social e a diversidade.

Concluo esse texto, apresentando que os maiores desafios da educação do campo, perpassam pela formação dos professores, o currículo fragmentado ou inexistente, além do acesso fácil ao ensino, o desinteresse pela pesquisa, e a falta de um vínculo próprio de interesse e engajamento para com o aluno. Por isso, e principalmente pelo os alunos do campo, acredita-se na existência de um currículo que venha a somar com os conhecimentos dos estudantes do campo, possibilitando diálogos com os conhecimentos já produzidos pela escola e os saberes produzidos nas comunidades, estabelecendo uma extensão do seu espaço para a sala de aula. 


\section{REFERÊNCIAS}

Arroyo, M. G; CAldart, R. S; MOLINA, M. C; (Orgs.) Por uma educação do campo. 3. ed. Petrópolis, RJ: Vozes, 2008.

ARROYO, M. G; Currículo, território em disputa. 5 ed. Petrópolis-RJ: Vozes, 2013.

ARAÚJO, I. X; SILVA, S. B; Educação do campo e a formação sociopolítica do educador. João Pessoa: Editora Universitária da UFPB, 2011.

CORDEIRO, G. K; Educação do Campo e Desenvolvimento: reflexões referenciadas nos artigos do II Encontro Nacional de Pesquisa em Educação do Campo. IN: MOLINA, Mônica Castagna. (Org.) Educação do Campo e Pesquisa II: Questões para Reflexão. Brasília: MDA/MEC, 2010.

DECRETO No 7.352 DE O4 DE NOVEMBRO DE 2010. Disponível em < https://portal.mec.gov.br/docman/marco-2012-pdf/10199-8-dereto-7352-de-4-de-novembrode-2010/file > acesso em 18/02/2017.

FORQUIN, J. C; Saberes Escolares: imperativos didáticos e dinâmicas sociais. Porto Alegre: Teoria e Educação, 1992.

FONSECA, J. J. S; Metodologia da pesquisa científica. Fortaleza: UEC, 2002.

FREIRE, P; PEDAGOGIA DA AUTONOMIA: Saberes necessários à prática educativa. ed. EGA, 1996.

GIL, A. C; Métodos e técnicas de pesquisa social - $6^{\text {a }}$ ed. - São Paulo : Atlas, 2008.

GIROUX, H; Os professores como intelectuais: rumo à Pedagogia Crítica da Aprendizagem. Porto Alegre: Artmed. 1997.

LEI DE DIRETRIZES DE BASES - lei de n 9.394, 20 de dezembro de 1996. Disponível em <https://presrepublica.jusbrasil.com.br/legislação/109224/lei-de-diretrizes-e-bases-lei9394-96 > acesso em 18/02/2017

LIMA, E. S; Educação do campo, currículo e diversidades culturais, espaço do currículo, v.6, n.3, p.608-619, Setembro a Dezembro de 2013.

MELO, J. C; Por entre as águas do sertão: currículo e educação ambiental das escolas rurais do Jalapão. São Paulo, 2011. Tese (Doutorado em Educação: Currículo), Pontifícia Universidade Católica de São Paulo (PUC - SP).

MINAYO, M. C. S; (org.) Pesquisa social: teoria, método e criatividade. $21^{\text {a }}$.ed. Petrópolis, RJ: Vozes, 2002. (Coleção temas sociais). 
MOREIRA, A. F; SILVA, T. T; Currículo, Cultura e Sociedade. São Paulo: Cortez, 1994.

PIMENTEL, A. P; In: MACEDO, R. S; Currículo, Diversidade e Equidade: luzes para uma educação intercrítica. Salvador: Edufba, 2007.

SANTOS, L; A construção do currículo: seleção do conhecimento escolar. Salto para o futuro. Currículo: conhecimento e cultura. Ano XIX, no 1, abril. 2009.

SANTOS, A. L; Educação Do Campo: Discursos Sobre Currículo, Identidades E Culturas. Dourados, MS: UFGD, 2015.

SAVIANI, D; O trabalho como princípio educativo frente às novas tecnologias. Petrópolis, RJ: Vozes, 1994.

SAVIANI, N; Saber Escolar, currículo e didática: problemas da unidade conteúdo/método no processo pedagógico. Campinas, SP: Autores Associados, 2003.

SILVA, T. T; Documentos de identidade: uma introdução às teorias de currículo. 2. ed. Belo Horizonte: Autêntica, 2010.

TRIVIÑOS, A. N. S; Introdução à pesquisa em ciências sociais: a pesquisa qualitativa em educação. São Paulo: Atlas, 1987

VEIGA, I. P. A; Escola, currículo e ensino. In: VEIGA, I. P. A; CARDOSO, M. H. F; (Org.) Escola Fundamental: currículo e ensino. Campinas - SP: Papirus, 1995.

YIN, R. K; Estudo de caso: planejamento e métodos. Trad. de Daniel Grassi 2. ed. Porto Alegre: Bookman, 2001.

Submetido em: 17/09/2018

Aprovado em: 07/12/2018 